\title{
Lumbar Stenosis: A Recent Update by Review of Literature
}

\author{
Seung Yeop Lee ${ }^{1}$, Tae-Hwan $\mathrm{Kim}^{1}$, Jae Keun $\mathrm{Oh}^{2}$, Seung Jin Lee ${ }^{1}$, Moon Soo Park ${ }^{1}$ \\ ${ }^{1}$ Department of Orthopaedic Surgery, Hallym University Sacred Heart Hospital, Hallym University College of Medicine, Anyang, Korea \\ ${ }^{2}$ Department of Neurosurgery, Hallym University Sacred Heart Hospital, Hallym University College of Medicine, Anyang, Korea
}

Degeneration of the intervertebral disc results in initial relative instability, hypermobility, and hypertrophy of the facet joints, particularly at the superior articular process. This finally leads to a reduction of the spinal canal dimensions and compression of the neural elements, which can result in neurogenic intermittent claudication caused by venous congestion and arterial hypertension around nerve roots. Most patients with symptomatic lumbar stenosis had neurogenic intermittent claudication with the risk of a fall. However, although the physical findings and clinical symptoms in lumbar stenosis are not acute, the radiographic findings are comparatively severe. Magnetic resonance imaging is a noninvasive and good method for evaluation of lumbar stenosis. Though there are very few studies pertaining to the natural progression of lumbar spinal stenosis, symptoms of spinal stenosis usually respond favorably to non-operative management. In patients who fail to respond to non-operative management, surgical treatments such as decompression or decompression with spinal fusion are required. Restoration of a normal pelvic tilt after lumbar fusion correlates to a good clinical outcome.

Keywords: Lumbar spine; Spinal stenosis

\section{Introduction}

Degeneration of the intervertebral disc results in initial relative instability and hypermobility of the facet joints $[1,2]$. This can lead to hypertrophy of the facet joint, particularly the superior articular process, resulting in reduced spinal canal dimensions and compressed neural elements (Fig. 1). The resultant venous congestion and hypertension around nerve roots are likely to be responsible for the symptom complex known as neurogenic intermittent claudication (NIC) [3].

\section{Pathogenesis}

Based on the pathology, spinal stenosis can be categorized into the congenital and the acquired forms [4]. Congenital spinal stenosis is composed of stenosis caused by achondroplasia and idiopathic stenosis. Acquired forms of spinal stenosis usually are degenerative, but can also be caused by combined congenital and degenerative stenosis, spondylolisthetic or spondylolytic stenosis, iatrogenic stenosis (such as post-laminectomy stenosis), post-traumatic stenosis, or metabolic stenosis (such as Paget disease) [4].

The most common type of spinal stenosis is caused by degenerative arthritis of the spine. This is most commonly localized to the facet joints and ligamentum flavum, with the resultant arthritic changes in the facet joints visible on radiographic studies $[5,6]$. Acquired stenosis of the degenerative type is brought on by changes in the three-joint complex, which consists of the disc, associated superior

Received Feb 9, 2015; Revised Feb 23, 2015; Accepted Feb 24, 2015

Corresponding author: Moon Soo Park

Department of Orthopaedic Surgery, Hallym University Sacred Heart Hospital, Hallym University College of Medicine, 22 Gwanpyeongro 170beon-gil, Dongan-gu, Anyang 14068, Korea

Tel: +82-31-380-6000, Fax: +82-31-380-6008, E-mail: amhangpark@gmail.com 
and inferior vertebral bodies, and the facet joints. Degeneration can start in any one of the joints (disc or facets), but eventually involves all three joints. The facets, which are diarthrodial joints, begin degenerating by developing synovitis [5]. As the synovitis progresses, the joint cartilage thins and the facet capsule loosens. Since this loosening allows for greater spinal motion, degeneration of the intervertebral disc is accelerated. As motion increases, osteophytes enlarge. Although the osteophytes can stabilize the motion segment, they can also narrow the spinal canal. Osteophytes on the superior articular facet narrow the lateral recess; osteophytes on the inferior articular facet narrow the central canal. The L4-5 level is involved most frequently.

Spinal stenosis can be categorized as central and lateral forms, according to the anatomical area of the spine affected. Central spinal stenosis denotes the involvement of the area between the facet joints, which is occupied by the dura mater and its contents. The most common symptom of central spinal stenosis is NIC. Lee et al. [7] classified the nerve root canal into three zones to clarify the anatomy and to describe the pathologic structures responsible for nerve root compression within the three zones: lateral recess, foraminal, and extraforaminal stenosis. The lateral recess, also known as "Lee's entrance zone," begins at the lateral border of the dura and extends to the medial border of the pedicle. This is where the nerve root exits the dura and courses distally and laterally under the superior articular facet [8]. Lee's midzone describes the foraminal region, which lies ventral to the pars. The dorsal root ganglion and ventral motor root occupy $30 \%$ of this space. Causes of stenosis in this area are pars defect with proliferative fibrocartilage or a lateral disc herniation. An $8 \%$ to $11 \%$ incidence of foraminal stenosis has been reported [912]. The most common roots involved were the fifth lumbar root (75\%), followed by the fourth root (15\%), and the third root (5.3\%) [12]. The L4 and L5 dorsal root ganglion are more commonly intraforaminal, and S1 dorsal root ganglion are found to be more cephalad or intraspinal $[13,14]$. The normal foraminal height varies from 20 to $23 \mathrm{~mm}$, whereas the width of the superior foramen varies from 8 to $10 \mathrm{~mm}$ [15]. The indicator of potential foraminal stenosis is a foraminal height of $15 \mathrm{~mm}$ or less [15]. The exit zone is identified as the area lateral to the facet joint. The nerve root is present in this location and can be compressed by a "far-lateral" disc, spondylolisthesis and associated subluxation or facet arthritis [16]. Central stenosis results from the hypertrophy of the inferior facet articular process of cephalic vertebra. Lateral recess and foraminal stenosis are the result of the hypertrophy of the
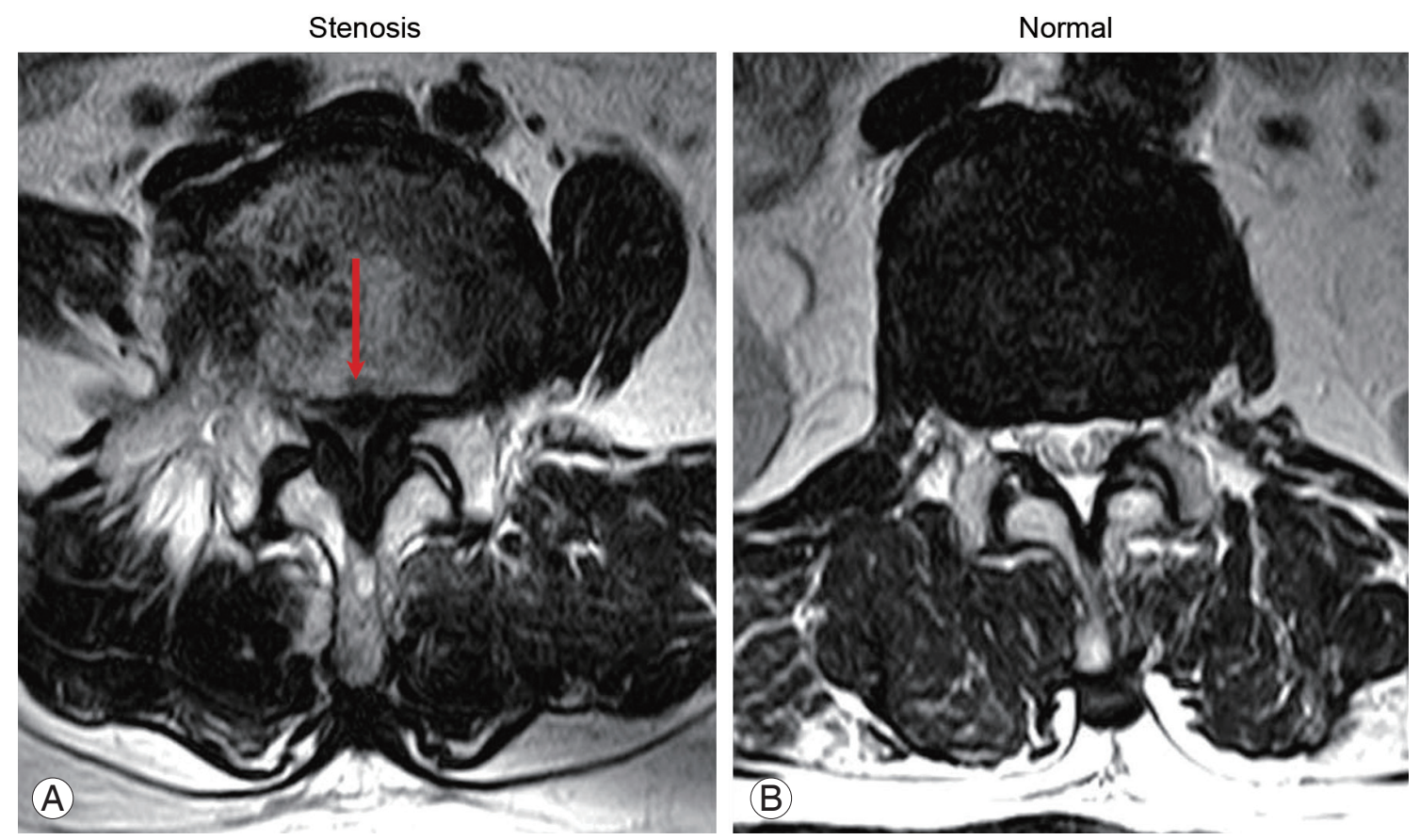

Fig. 1. Hypertrophy of the facet joint, particularly at the superior articular process, resulting spinal canal stenosis and compression of the neural elements (arrow) (A) compared to normal lumbar spine (B). 
superior facet articular process of caudal vertebra. NIC resulted from the mechanical compression to the nerve root, the artery and vein surrounding the nerve root, provoking venous congestion or arterial ischemia of nerve root due to hypertension [17]. This vascular compromise leads to an ischemic neuritis that contributes to the clinical symptoms of stenosis [3]. Additionally, constriction of the cauda equina has experimentally been shown to lead to demyelination of the nerve roots [18]. This can play a part in creating unremitting pain.

\section{Clinical Presentation}

The most common form of degenerative stenosis generally becomes symptomatic during or after the seventh decade of life [19]. It is more common in women than in men [20]. Associated cervical stenosis is seen in patients with lumbar stenosis [21]. Although the physical findings and clinical symptoms of spinal stenosis are not acute, the radiographic findings are comparatively quite severe. In a study population of 100 patients, Amundsen et al. [22] found the occurrence of back pain and sciatica in $95 \%$, and claudication in $91 \%$ of the patients. NIC usually had bilateral leg complaints. The distribution of pain in the lower extremities is dependent on the area of stenosis. It improves with trunk flexion, sitting, stooping or lying, and aggravates with prolonged standing or lumbar extension. As the condition becomes more advanced, sitting or lying down are less helpful in relieving the pain. In severe cases, rest pain or a neurogenic bladder can develop [23]. Therefore, the clinician must inquire about changes in bowel and bladder function, including the presence of urgency, frequency, and loss of control. If any of these complaints are present, a full urologic work-up is indicated. In patients with central stenosis, symptoms usually involve both the buttocks and both the posterior thighs in a non-dermatomal distribution. With lateral recess stenosis, symptoms are usually found dermatomal because specific nerves are compressed. Patients with lateral recess stenosis may have more pain during rest and at night, but more walking tolerance than patients with central stenosis. However, in general, physical findings with all forms of spinal stenosis are inconsistent. Straight leg raising and femoral nerve stretching test are usually normal [24]. The neurological examination is also usually normal, but some abnormality may be detected if the patient is allowed to walk to the limit of pain. The gait and posture after walking may reveal a positive "stoop test" [25]. This test is done by asking the patient to walk briskly [25]. As the pain intensifies, the patient may complain of sensory symptoms followed by motor symptoms [25]. If the patient is asked to continue to walk, he or she may assume a stooped posture and the symptoms may be eased [25]. If the patient sits in a chair bent forward, the same resolution of symptoms occurs [25].

In addition, patients with symptomatic lumbar stenosis have a risk of falling [26]. Evaluation of an age- and weight-matched case control study was conducted. The study consisted of two groups: 40 patients with symptomatic lumbar spinal stenosis and 40 patients with advanced osteoarthritis in both knees. The two groups were compared based on the results of functional mobility tests, such as a six-meter-walk test, sit-to-stand test, alternativestep test, and timed up and go test [26]. The patients with symptomatic lumbar stenosis had decreased functions of six-meter-walk test and sit-to-stand test [26].

\section{Differential Diagnosis}

It is important to differentiate the symptoms of vascular claudication from those of neurogenic claudication (Table 1). Patients with vascular claudication have a decreased or absent peripheral arterial pulse, such as dorsalis pedis. Vascular symptoms typically are relieved after a short rest (5 minutes) or while still standing; sitting or bending is not required. Symptoms get aggravated whilst walking uphill or riding a stationary bicycle. Neurogenic claudication improves with sitting and worsens with lumbar extension [27].

The common conditions confused with spinal stenosis are vascular claudication, hip joint problem [28] and peripheral neuropathy. Patients with evidence of both vascular claudication and spinal stenosis are more difficult to manage [29]. Consultation with a vascular surgeon can help to determine whether treatment of the vascular or spinal problem should take precedence. Electrodiagnostic studies should be used if a diagnosis of neuropathy is suspected, especially in patients with peripheral neuropathy. Differential diagnosis can also be aided by the use of exercise treadmill testing [30].

Spinal stenosis, with its insidious onset, chronicity, and bilaterality, is easily distinguished from other spinal conditions. Herniated discs generally occur in a younger patient population. The pain distribution is usually uni- 
Table 1. Differentiation of symptoms of vascular claudication from those of neurogenic claudication

\begin{tabular}{|c|c|c|}
\hline Evaluation & Vascular & Neurogenic \\
\hline Walking distance & Fixed & Variable \\
\hline Palliative factor & Standing & Sitting/bending \\
\hline Provocative factor & Walking & Walking/standing \\
\hline Walking uphill & Painful & Painless \\
\hline Bicycle test & Positive (painful) & Negative \\
\hline Pulse & Absent & Present \\
\hline Skin & Loss of hair; shiny & - \\
\hline Weakness & Rarely & Occasionally \\
\hline Back pain & Occasionally & Commonly \\
\hline Back motion & - & Limited \\
\hline Pain character & Cramping—distal to proximal & Numbness, aching — proximal to distal \\
\hline Atrophy & Uncommon & Occasionally \\
\hline
\end{tabular}

lateral and neurological findings are common. Although a central disc herniation may mimic the pain of a classic spinal stenosis, it is usually more abrupt in onset, with increased pain while sitting, and has associated neurological findings and positive sciatic stretch tests. These features usually help in distinguishing a central disc herniation from spinal stenosis.

When the differential diagnosis is difficult, specialized medical imaging and electrodiagnostic testing can be helpful in determining the source of pain. These tests are discussed further in the section on preoperative evaluation.

\section{Imaging Evaluation}

Two practical definitions to describe stenosis are absolute stenosis (when the mid-sagittal diameter of the canal is less than $10 \mathrm{~mm}$ ) or relative stenosis (when the mid-sagittal diameter of the canal is between $10 \mathrm{~mm}$ and $13 \mathrm{~mm}$ ) [31]. In congenital and developmental stenosis, the primary problem is the inadequate canal size. Normal canal size has been defined as having a mid-sagittal diameter of more than $11.5 \mathrm{~mm}$ and an area more than $1.45 \mathrm{~cm}^{2}$ [32]. Although these measurements are useful guidelines, the actual symptoms do not always correspond to canal size; the degree of impingement on the neural elements by the bony and soft tissues has more importance [33].

Plain radiographs are useful in identifying fractures due to trauma, and helpful in evaluating alignment, loss of disc height and osteophyte formation. They enable us to

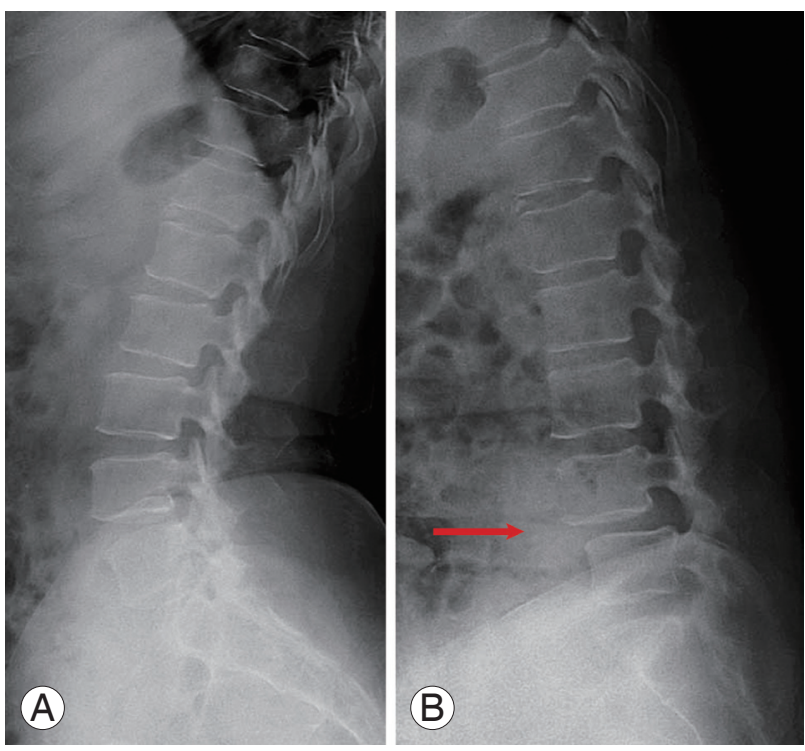

Fig. 2. A reversal of the normal trapezoidal disc geometry with widening posteriorly and narrowing anteriorly in the dynamic view may indicate instability (arrow) (B) compared to the view with flexed posture (A).

find the defect of pars interarticularis with oblique views, and instability with dynamic view. Anteroposterior views in standing position, which include the hip joints, should also be obtained. Translation of more than $5 \mathrm{~mm}$, or rotation of more than 10 to 15 degrees in the dynamic view, indicates instability. A reversal of the normal trapezoidal disc geometry with widening posteriorly and narrowing anteriorly may also indicate instability (Fig. 2). 
Magnetic resonance imaging (MRI) is a noninvasive and suitable method to evaluate lateral recess stenosis. Because of its ability to differentiate tissues and assess the status of the intervertebral disc, it can replace computed tomography (CT) scans for many patients [34]. It is as accurate as CT and myelography in diagnosing spinal stenosis, while being more sensitive at identifying disc degeneration [35]. Midline T2-sagittal images may be useful in diagnosing central stenosis by noting sagittal narrowing of the intervertebral canal (Fig. 3). Sagittal T1weighted images are evaluated with particular attention focused on the foramen. An absence of normal fat around the root indicates foraminal stenosis (Fig. 4). Extraforaminal stenosis is identified on axial T1-weighted images by obliteration of the normal interval of fat between the disc and nerve root (Fig. 5).

Water soluble myelography followed by CT scan is also useful [36]. This combined study gives an excellent picture of the central and lateral canal and defines any extradural cause of compression. It is best suited for patients

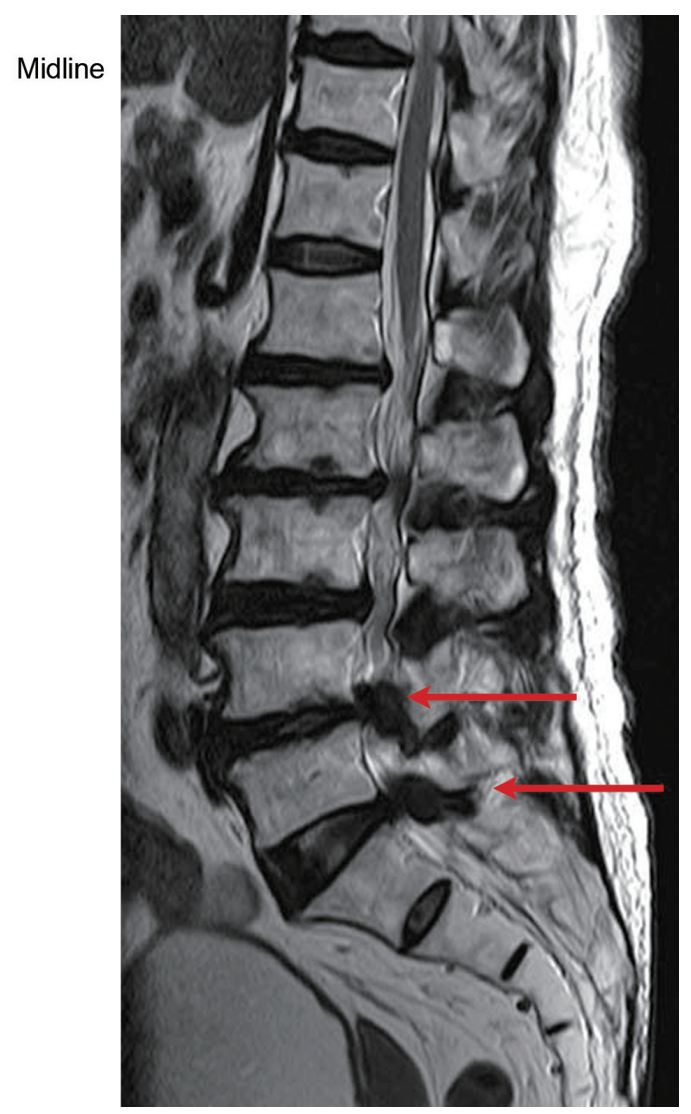

Fig. 3. Midline T2-sagittal images may be useful in diagnosing central stenosis by noting sagittal narrowing of the intervertebral canal (arrows). with dynamic stenosis, postoperative leg pain, severe scoliosis or spondylolisthesis, metallic implants, any contraindications to MRI, and lower extremity symptoms in the absence of suitable findings on MRI (Fig. 6). However, direct measurement of the bony canal on CT images often gives an inaccurate assessment of the degree of stenosis [37].

Boden et al. [38] noted abnormal findings in $67 \%$ of asymptomatic patients evaluated by MRI. In patients older than 60 years, $57 \%$ of MRI scans were abnormal, including $36 \%$ of patients with herniated nucleus pulposus, and $21 \%$ with spinal stenosis [38]. Hence, findings of MRI should be matched with the symptoms and signs of patients having neurogenic claudication or radiculopathy. In addition, there is no correlation between the severity of clinical stenosis and the severity of symptoms of spinal stenosis [39]. In patients with moderate radiographic stenosis obliterating one-third to two-thirds of spinal canal on axial images, only $9.9 \%$ of patients showed symptoms [39]. In patients with severe radiographic stenosis, where more than two-thirds of spinal canal was obliterated on axial images, only $17.5 \%$ of patients had symptoms [39].

When compared with 40 patients without NIC, 53 patients having NIC due to lumbar stenosis had positive sagittal balance, loss of lumbar lordosis, and increased pelvic tilt [40]. In addition, the patients with degenerative

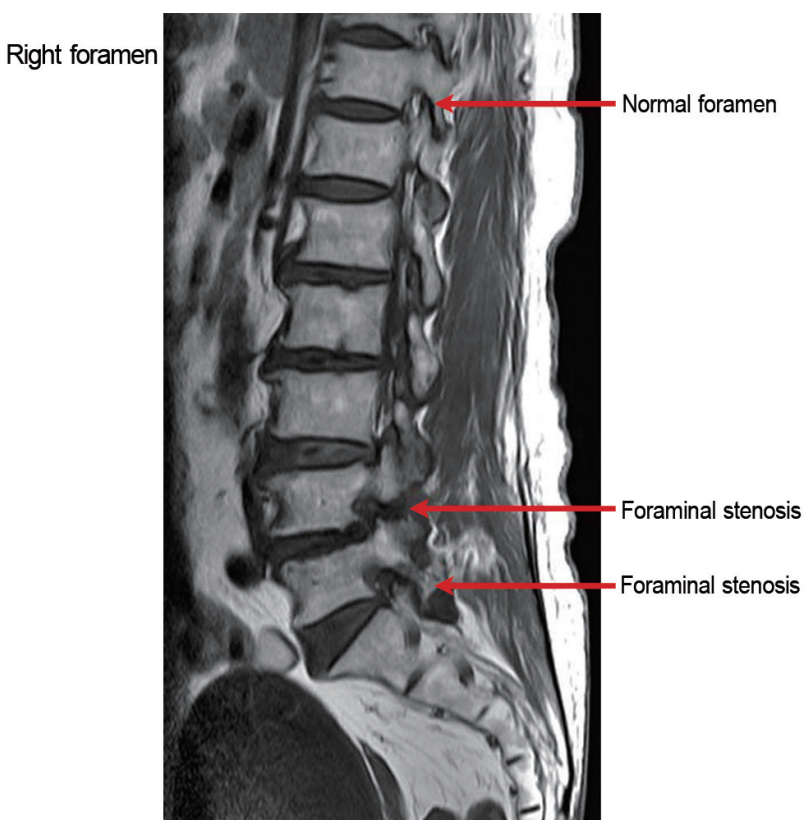

Fig. 4. An absence of normal fat around the root indicates foraminal stenosis on sagittal T1-weighted images (arrows). 


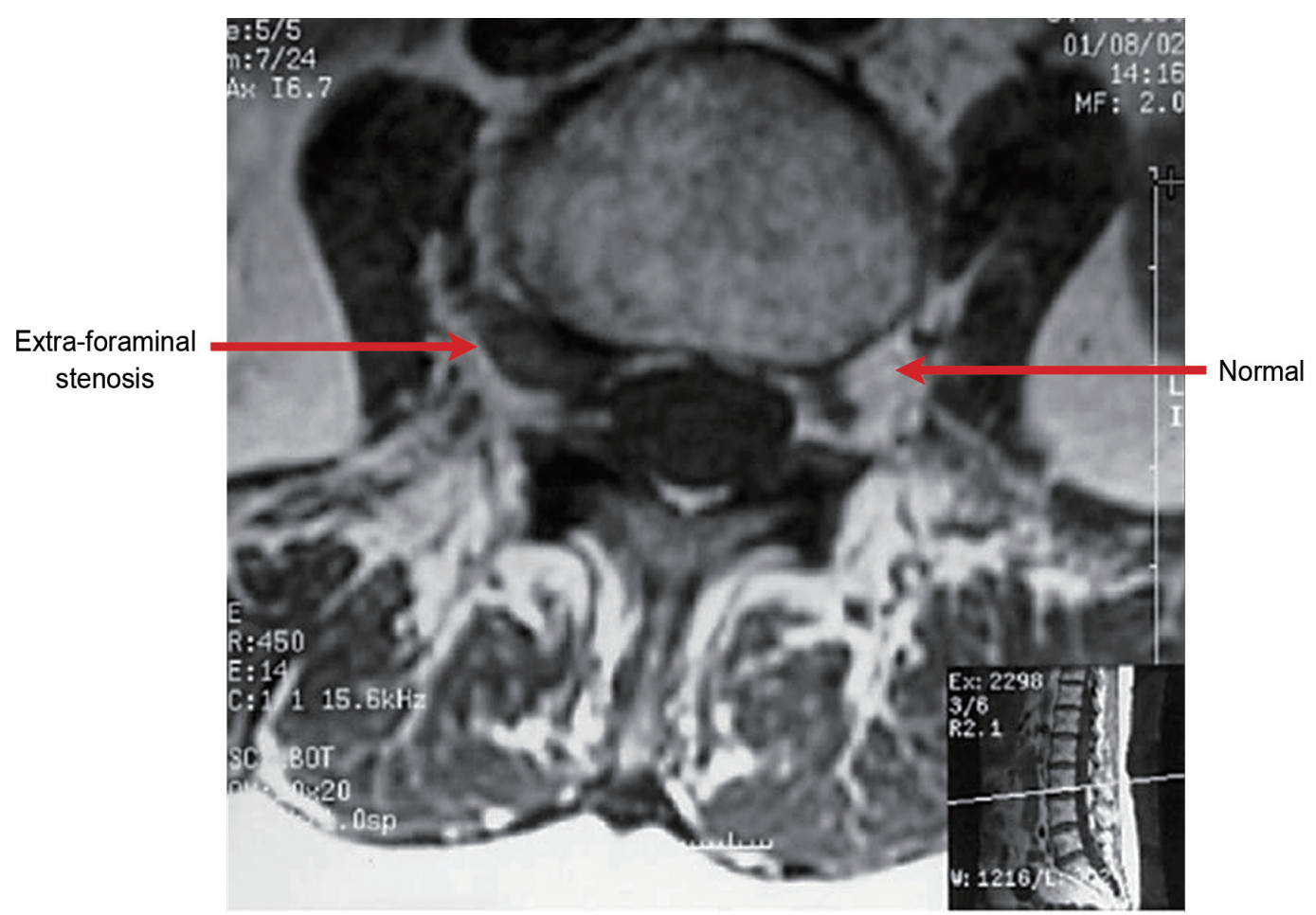

Fig. 5. Extraforaminal stenosis is identified on axial T1-weighted images by obliteration of the normal interval of fat between the disc and nerve root (arrow) at the lumbar 3-4 disc level (box).
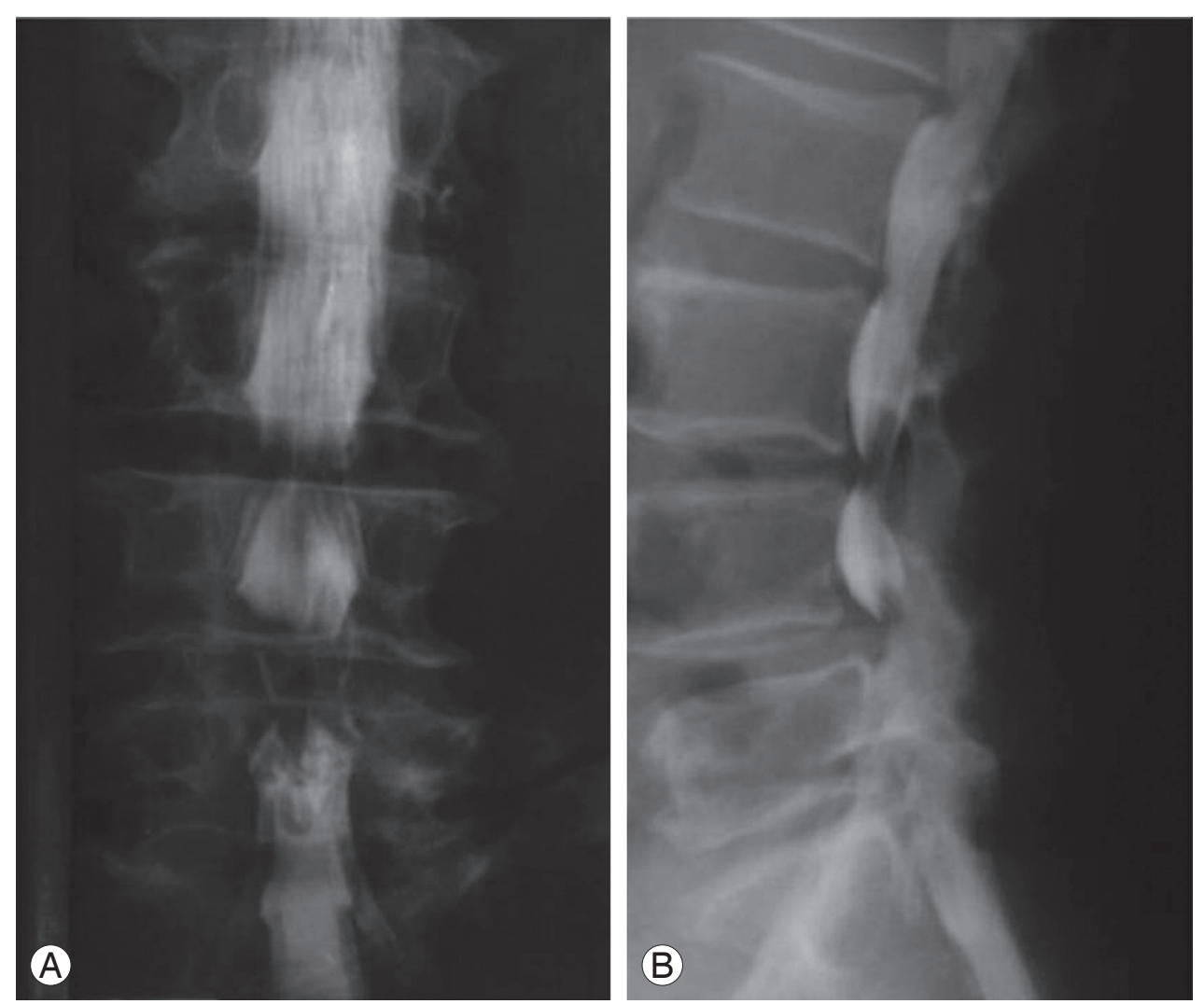

Fig. 6. Myelography of lumbar spine in anteroposterior view (A) and lateral view (B). 
Table 2. Randomized controlled studies compared clinical outcomes of surgical and conservative treatment for spinal stenosis (surgery: decompressive surgery only)

\begin{tabular}{|c|c|c|c|c|}
\hline Author & Number ${ }^{a)}$ & $\begin{array}{l}\text { Follow-up } \\
\text { (yr) }\end{array}$ & Outcome measure & Clinical outcome \\
\hline Atlas et al. [46] & $81 / 67$ & 1 & $\begin{array}{l}\text { VAS, satisfaction, stenosis index, } \\
\text { SF-36 }{ }^{c} \text {, modified Roland scale }\end{array}$ & $\begin{array}{l}\text { Surgery had better improvement for all } \\
\text { measurements (radicular and back pain). }\end{array}$ \\
\hline Atlas et al. [47] & $67 / 52$ & 4 & Same as above & Same as above. \\
\hline Atlas et al. [48] & $53 / 38$ & 10 & Same as above & $\begin{array}{l}\text { No difference for back pain, satisfaction. } \\
\text { Surgery had better improvement for radicular pain. }\end{array}$ \\
\hline $\begin{array}{l}\text { Amundsen et al. } \\
\text { [22] }\end{array}$ & $22 / 68$ & 10 & $\begin{array}{l}\text { VAS, satisfaction, claudication } \\
\text { distance }\end{array}$ & No difference for claudication, back pain. \\
\hline Chang et al. [49] & $51 / 35$ & 10 & $\begin{array}{l}\text { Symptom index, satisfaction, SF-36, } \\
\text { modified Roland Scale }\end{array}$ & $\begin{array}{l}\text { No difference for back pain, satisfaction. } \\
\text { Surgery had better improvement for radicular } \\
\text { pain, functional status. }\end{array}$ \\
\hline
\end{tabular}

VAS, visual analogue scale; SF-36, short form 36.

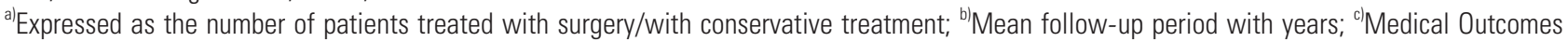
Study SF-36 questionnaire.

disc disease $(n=32)$, lumbar disc herniation $(n=25)$, and degenerative spondylolisthesis $(\mathrm{n}=28)$ had positive sagittal balance, loss of lumbar lordosis, decreased sacral slope and increased pelvic tilt when compared with a control population of 154 asymptomatic adults [41]. In another study, at 6 months after discectomy, the positive sagittal balance, loss of lumbar lordosis and decreased sacral slope in 61 patients with lumbar disc herniation, had recovered to almost the same level as the control group of 60 asymptomatic adults [42].

Literature review to understand the relationship between sagittal balance and clinical outcomes in surgical treatment of degenerative spinal diseases (including degenerative stenosis, degenerative spondylolisthesis, degenerative scoliosis and degenerative kyphosis), revealed an increase in pelvic tilt after lumbar fusion correlated with postoperative back pain [43]. Restoration of a normal pelvic tilt after surgery correlates with a good clinical outcome [43]. Similarly, in a retrospective study of 18 patients who underwent decompression with spinal fusion after a diagnosis of degenerative spondylolisthesis, the patients showing an improvement in the pelvic tilt after lumbar fusion were found to achieve a good clinical outcome of visual analogue pain score and Oswestry disability index [44].

\section{Natural Progression}

Studies pertaining to the natural progression of lumbar spinal stenosis are few, with a limited number of patients per group. Johnsson et al. [45] reported that 19 of $27 \mathrm{pa}-$ tients $(70 \%)$ with moderate, untreated spinal stenosis $(\geq 11$ $\mathrm{mm}$ anteroposterior canal diameter) remained unchanged after 4 years of observation; 4 patients (15\%) showed an improvement, and 4 patients (15\%) deteriorated without serious sequelae.

There have been five randomized controlled studies comparing the clinical outcomes of surgical and conservative treatment for spinal stenosis (Table 2) [22,4649]. In the short-term follow-up of 1 to 4 years, patients treated surgically had better clinical results with radicular and low back pain $[46,47]$. However, in the long-term follow-up of 10 years, there were no significant differences of clinical results between surgery and conservative management for lower back pain, since it occurs due to degenerative changes $[22,48,49]$. In the long-term followup of 10 years, the patients treated surgically had a better improvement for radicular pain [22,46-49]. During initial follow up of 1-5 years in the long-term follow-up study, surgical intervention had better improvement for all measurements of radicular and back pain [49].

\section{Treatment}

Symptoms of spinal stenosis usually respond favorably to non-operative management [50]. Despite symptoms of back pain, radiculopathy, or neurogenic claudication, conservative management is successful in most patients 
and recommended for an initial treatment. Conservative measures usually include bed rest, nonsteroidal antiinflammatory drug, acetaminophen, exercise program, aerobic fitness and epidural steroid injections.

Conservative treatment is appropriate for patients with moderate pain, $50 \%$ of whom have pain relief in less than 3 months. Operative treatment is indicated for patients with severe pain and constant neurologic symptoms, and in patients where conservative treatment has failed [51]. Based on the results of a pilot study with 55 patients having lumbar stenosis, gabapentin treatment resulted in an increase in the walking distance, a decrease in the visual analogue scales of back pain and leg pain, and an improvement of sensory deficit, when compared to the standard treatment [52].

Surgery for spinal stenosis consists of either decompression alone, or decompression with spinal fusion. Decompression by laminectomy is the treatment of choice for central or lateral recess stenosis. On the other hand, fusion is required if foraminal stenosis is present. During the decompressive surgery, specific attention should be paid not to injure the pars interarticularis [53]. Whenever possible, the source of pain should be localized with selective root blocks preoperatively, to allow a more focal decompression. A good approach is to start the decompression at a point of lesser stenosis and work towards the area of most severe stenosis. This often frees the neural structures enough to make the final decompression simpler and decreases the risk of damage to dura or nerve roots. It is desirable to attain decompression with minimally invasive techniques, and preserving the paraspinal muscle, spinous processes, supraspinous and interspinous ligaments [54]. A microscope or magnifying loupes and tubular retractor system are helpful [54].

Fusion is required if there is excessive facetectomy, as more than $50 \%$ compromises stability [55], or if stenosis is combined with isthmic or degenerative spondylolisthesis [56], scoliosis, kyphosis or synovial facet joint cyst. Other indications for fusion include adjacent segment degeneration after prior fusion, and recurrent stenosis or herniated disc after decompressed site [57]. If fusion is likely, the hips should remain extended to prevent positional kyphosis.

In the United States, the rate of patients who underwent decompression merely on a diagnosis of lumbar stenosis, has decreased from $58 \%$ in 2004 to $49 \%$ in 2009 [58]. However, the rate of patients who underwent decompression with spinal fusion has increased from $21 \%$ in 2004 to
$31 \%$ in 2009 [58]. This means that lack of consensus and worldwide variability exists in making a surgical decision for patients with lumbar stenosis.

Usually, $60 \%$ to $90 \%$ of patients have relief of their symptoms after surgical or conservative treatments $[22,59,60]$. However, back pain may persist due to a preexisting degenerative arthritis. In patients with neurologic abnormality, $90 \%$ of patients usually experience relief after surgery [59]. Prognostic factors for better results are stenosis at a single level, weakness of less than 6 weeks duration, mono-radiculopathy, and where preoperative symptoms were relieved by postural change $[22,60]$. However, the severity of narrowing is not a prognostic factor for better surgical outcome [22]. In a retrospective study for 10-year survival, patients older than 50 years who underwent either spinal decompression or decompression with spinal fusion after the diagnosis of spinal stenosis, the mortality was reduced as compared to the corresponding portion of the general population [61].

\section{Conclusions}

Patients with symptomatic stenosis may present with one or more of a combination of axial pain, radiculopathy and neurogenic claudication. The long-term outcome of patients with lumbar spinal stenosis treated conservatively was equivalent to the patients treated surgically. Decompressive surgery is the gold standard for treatment of central or lateral recess lumbar stenosis. Additional fusion is required if there is associated instability, resection of more than $50 \%$ of the facet joints, degenerative spondylolisthesis, scoliosis, kyphosis and previous decompression at the same level.

\section{Conflict of Interest}

No potential conflict of interest relevant to this article was reported.

\section{References}

1. Holm S. Pathophysiology of disc degeneration. Acta Orthop Scand Suppl 1993;251:13-5.

2. Rauschning W. Pathoanatomy of lumbar disc degeneration and stenosis. Acta Orthop Scand Suppl 1993; 251:3-12.

3. Rauschning W. Normal and pathologic anatomy of 
the lumbar root canals. Spine (Phila Pa 1976) 1987; 12:1008-19.

4. Arnoldi CC, Brodsky AE, Cauchoix J, et al. Lumbar spinal stenosis and nerve root entrapment syndromes. Definition and classification. Clin Orthop Relat Res 1976;(115):4-5.

5. Yong-Hing K, Kirkaldy-Willis WH. The pathophysiology of degenerative disease of the lumbar spine. Orthop Clin North Am 1983;14:491-504.

6. Yoshida M, Shima K, Taniguchi Y, Tamaki T, Tanaka T. Hypertrophied ligamentum flavum in lumbar spinal canal stenosis. Pathogenesis and morphologic and immunohistochemical observation. Spine (Phila Pa 1976) 1992;17:1353-60.

7. Lee CK, Rauschning W, Glenn W. Lateral lumbar spinal canal stenosis: classification, pathologic anatomy and surgical decompression. Spine (Phila Pa 1976) 1988;13:313-20.

8. Kirkaldy-Willis WH, Wedge JH, et al. Lumbar spinal nerve lateral entrapment. Clin Orthop Relat Res 1982;(169):171-8.

9. Kunogi J, Hasue M. Diagnosis and operative treatment of intraforaminal and extraforaminal nerve root compression. Spine (Phila Pa 1976) 1991;16:1312-20.

10. Porter RW, Hibbert C, Evans C. The natural history of root entrapment syndrome. Spine (Phila Pa 1976) 1984;9:418-21.

11. Vanderlinden RG. Subarticular entrapment of the dorsal root ganglion as a cause of sciatic pain. Spine (Phila Pa 1976) 1984;9:19-22.

12. Jenis LG, An HS. Spine update: lumbar foraminal stenosis. Spine (Phila Pa 1976) 2000;25:389-94.

13. Hasegawa T, Mikawa Y, Watanabe R, An HS. Morphometric analysis of the lumbosacral nerve roots and dorsal root ganglia by magnetic resonance imaging. Spine (Phila Pa 1976) 1996;21:1005-9.

14. Kikuchi S, Sato K, Konno S, Hasue M. Anatomic and radiographic study of dorsal root ganglia. Spine (Phila Pa 1976) 1994;19:6-11.

15. Hasegawa T, An HS, Haughton VM, Nowicki BH. Lumbar foraminal stenosis: critical heights of the intervertebral discs and foramina: a cryomicrotome study in cadavera. J Bone Joint Surg Am 1995;77:328.

16. Wiltse LL, Guyer RD, Spencer CW, Glenn WV, Porter IS. Alar transverse process impingement of the L5 spinal nerve: the far-out syndrome. Spine (Phila Pa
1976) 1984;9:31-41.

17. Rydevik B, Brown MD, Lundborg G. Pathoanatomy and pathophysiology of nerve root compression. Spine (Phila Pa 1976) 1984;9:7-15.

18. Schonstrom N, Hansson T. Pressure changes following constriction of the cauda equina: an experimental study in situ. Spine (Phila Pa 1976) 1988;13:385-8.

19. Paine KW. Clinical features of lumbar spinal stenosis. Clin Orthop Relat Res 1976;(115):77-82.

20. Spengler DM. Degenerative stenosis of the lumbar spine. J Bone Joint Surg Am 1987;69:305-8.

21. Choudhury AR, Taylor JC. The cervicolumbar syndrome. Ann R Coll Surg Engl 1980;62:200-2.

22. Amundsen T, Weber H, Nordal HJ, Magnaes B, Abdelnoor M, Lilleas F. Lumbar spinal stenosis: conservative or surgical management? A prospective 10year study. Spine (Phila Pa 1976) 2000;25:1424-35.

23. Smith AY, Woodside JR. Urodynamic evaluation of patients with spinal stenosis. Urology 1988;32:474-7.

24. Natelson SE. The injudicious laminectomy. Spine (Phila Pa 1976) 1986;11:966-9.

25. Dyck $P$. The stoop-test in lumbar entrapment radiculopathy. Spine (Phila Pa 1976) 1979;4:89-92.

26. Kim HJ, Chun HJ, Han CD, et al. The risk assessment of a fall in patients with lumbar spinal stenosis. Spine (Phila Pa 1976) 2011;36:E588-92.

27. Inufusa A, An HS, Lim TH, Hasegawa T, Haughton VM, Nowicki BH. Anatomic changes of the spinal canal and intervertebral foramen associated with flexion-extension movement. Spine (Phila Pa 1976) 1996;21:2412-20.

28. McNamara MJ, Barrett KG, Christie MJ, Spengler DM. Lumbar spinal stenosis and lower extremity arthroplasty. J Arthroplasty 1993;8:273-7.

29. Dodge LD, Bohlman HH, Rhodes RS. Concurrent lumbar spinal stenosis and peripheral vascular disease: a report of nine patients. Clin Orthop Relat Res 1988;(230):141-8.

30. Fritz JM, Erhard RE, Delitto A, Welch WC, Nowakowski PE. Preliminary results of the use of a twostage treadmill test as a clinical diagnostic tool in the differential diagnosis of lumbar spinal stenosis. J Spinal Disord 1997;10:410-6.

31. Eisenstein S. The morphometry and pathological anatomy of the lumbar spine in South African negroes and caucasoids with specific reference to spinal stenosis. J Bone Joint Surg Br 1977;59:173-80. 
32. Ullrich CG, Binet EF, Sanecki MG, Kieffer SA. Quantitative assessment of the lumbar spinal canal by computed tomography. Radiology 1980;134:137-43.

33. Helms CA. CT of the lumbar spine: stenosis and arthrosis. Comput Radiol 1982;6:359-69.

34. Crawshaw C, Kean DM, Mulholland RC, et al. The use of nuclear magnetic resonance in the diagnosis of lateral canal entrapment. J Bone Joint Surg Br 1984; 66:711-5.

35. Schnebel B, Kingston S, Watkins R, Dillin W. Comparison of MRI to contrast CT in the diagnosis of spinal stenosis. Spine (Phila Pa 1976) 1989;14:332-7.

36. Uden A, Johnsson KE, Jonsson K, Pettersson H. Myelography in the elderly and the diagnosis of spinal stenosis. Spine (Phila Pa 1976) 1985;10:171-4.

37. Bolender NF, Schonstrom NS, Spengler DM. Role of computed tomography and myelography in the diagnosis of central spinal stenosis. J Bone Joint Surg Am 1985;67:240-6.

38. Boden SD, Davis DO, Dina TS, Patronas NJ, Wiesel SW. Abnormal magnetic-resonance scans of the lumbar spine in asymptomatic subjects: a prospective investigation. J Bone Joint Surg Am 1990;72:403-8.

39. Ishimoto Y, Yoshimura N, Muraki S, et al. Associations between radiographic lumbar spinal stenosis and clinical symptoms in the general population: the Wakayama Spine Study. Osteoarthritis Cartilage 2013;21:783-8.

40. Suzuki H, Endo K, Kobayashi H, Tanaka H, Yamamoto $\mathrm{K}$. Total sagittal spinal alignment in patients with lumbar canal stenosis accompanied by intermittent claudication. Spine (Phila Pa 1976) 2010;35:E344-6.

41. Barrey C, Jund J, Noseda O, Roussouly P. Sagittal balance of the pelvis-spine complex and lumbar degenerative diseases: a comparative study about 85 cases. Eur Spine J 2007;16:1459-67.

42. Endo K, Suzuki H, Tanaka H, Kang Y, Yamamoto K. Sagittal spinal alignment in patients with lumbar disc herniation. Eur Spine J 2010;19:435-8.

43. Le Huec JC, Faundez A, Dominguez D, Hoffmeyer $\mathrm{P}$, Aunoble S. Evidence showing the relationship between sagittal balance and clinical outcomes in surgical treatment of degenerative spinal diseases: a literature review. Int Orthop 2015;39:87-95.

44. Kim MK, Lee SH, Kim ES, Eoh W, Chung SS, Lee CS. The impact of sagittal balance on clinical results after posterior interbody fusion for patients with degen- erative spondylolisthesis: a pilot study. BMC Musculoskelet Disord 2011;12:69.

45. Johnsson KE, Rosen I, Uden A. The natural course of lumbar spinal stenosis. Clin Orthop Relat Res 1992;(279):82-6.

46. Atlas SJ, Deyo RA, Keller RB, et al. The Maine Lumbar Spine Study, Part III. 1-year outcomes of surgical and nonsurgical management of lumbar spinal stenosis. Spine (Phila Pa 1976) 1996;21:1787-94.

47. Atlas SJ, Keller RB, Robson D, Deyo RA, Singer DE. Surgical and nonsurgical management of lumbar spinal stenosis: four-year outcomes from the maine lumbar spine study. Spine (Phila Pa 1976) 2000;25:55662.

48. Atlas SJ, Keller RB, Wu YA, Deyo RA, Singer DE. Long-term outcomes of surgical and nonsurgical management of lumbar spinal stenosis: 8 to 10 year results from the maine lumbar spine study. Spine (Phila Pa 1976) 2005;30:936-43.

49. Chang Y, Singer DE, Wu YA, Keller RB, Atlas SJ. The effect of surgical and nonsurgical treatment on longitudinal outcomes of lumbar spinal stenosis over 10 years. J Am Geriatr Soc 2005;53:785-92.

50. Theodoridis T, Kramer J, Kleinert H. Conservative treatment of lumbar spinal stenosis: a review. Z Orthop Unfall 2008;146:75-9.

51. Onel D, Sari H, Donmez C. Lumbar spinal stenosis: clinical/radiologic therapeutic evaluation in $145 \mathrm{pa}-$ tients: conservative treatment or surgical intervention? Spine (Phila Pa 1976) 1993;18:291-8.

52. Yaksi A, Ozgönenel L, Ozgonenel B. The efficiency of gabapentin therapy in patients with lumbar spinal stenosis. Spine (Phila Pa 1976) 2007;32:939-42.

53. Shenkin HA, Hash CJ. Spondylolisthesis after multiple bilateral laminectomies and facetectomies for lumbar spondylosis: follow-up review. J Neurosurg 1979;50:45-7.

54. Park Y, Ha JW. Comparison of one-level posterior lumbar interbody fusion performed with a minimally invasive approach or a traditional open approach. Spine (Phila Pa 1976) 2007;32:537-43.

55. Abumi K, Panjabi MM, Kramer KM, Duranceau J, Oxland T, Crisco JJ. Biomechanical evaluation of lumbar spinal stability after graded facetectomies. Spine (Phila Pa 1976) 1990;15:1142-7.

56. Fischgrund JS, Mackay M, Herkowitz HN, Brower R, Montgomery DM, Kurz LT. 1997 Volvo Award 
winner in clinical studies. Degenerative lumbar spondylolisthesis with spinal stenosis: a prospective, randomized study comparing decompressive laminectomy and arthrodesis with and without spinal instrumentation. Spine (Phila Pa 1976) 1997;22:280712.

57. Whitecloud TS 3rd, Davis JM, Olive PM. Operative treatment of the degenerated segment adjacent to a lumbar fusion. Spine (Phila Pa 1976) 1994;19:531-6.

58. Bae HW, Rajaee SS, Kanim LE. Nationwide trends in the surgical management of lumbar spinal stenosis. Spine (Phila Pa 1976) 2013;38:916-26.
59. Guigui P, Benoist M, Delecourt C, Delhoume J, Deburge A. Motor deficit in lumbar spinal stenosis: a retrospective study of a series of 50 patients. J Spinal Disord 1998;11:283-8.

60. Ganz JC. Lumbar spinal stenosis: postoperative results in terms of preoperative posture-related pain. J Neurosurg 1990;72:71-4.

61. Kim HJ, Lee HM, Kim HS, et al. Life expectancy after lumbar spine surgery: one- to eleven-year follow-up of 1015 patients. Spine (Phila Pa 1976) 2008;33:211621. 